\title{
Projected water demands by 2050 in South Gobi region of Mongolia
}

\author{
Ayurzana Badarch*1, Elbegjargal Ariya ${ }^{2}$, Ariun-Erdene Dashjamts ${ }^{2}$ and Batzorig Gansukh $^{1}$ \\ ${ }^{1}$ School of Civil Engineering and Architecture, Mongolian University of Science and \\ Technology, Ulaanbaatar, Mongolia \\ ${ }^{2}$ School of Applied Sciences, Mongolian University of Science and \\ Technology, Ulaanbaatar, Mongolia
}

ARTICLE INFO: Received: 4 Mar, 2021; Accepted: 24 Sep, 2021

\begin{abstract}
The South Gobi region (including Umnugovi, Dundgovi and Dornogovi aimags provinces) of Mongolia is becoming a leading region of the nation's economic and social development. Water resources play an important role in ensuring sustainable economic development of the South Gobi region. In the South Gobi region, lack of proven groundwater resources, data on water extraction and consumption makes it difficult to accurately identify risks and to manage limited resources for sustainable development. Based on the available historical data between 2015 and 2019 on water resources and water use, the water demand in this region has been projected up to the year 2050 on the basis of dynamic modelling of water management, including major stakeholders, country's sustainable economic development vision up to the year 2050, and the impact of climate change. The model predicts continued increasing demand for mining, agricultural, industrial and social services and rural water demands, while gradual decline for the livestock water demand was projected after the gradual increase in the first half of the period. Basing on the system dynamic modelling of water management, it can be said that the groundwater resources of the South Gobi region may not be able to meet the above needs after 2037. Economically feasible measures and managements to prevent the risk of water scarcity before water shortage happens are proposed based on the results of the model.
\end{abstract}

Keywords: The South Gobi region; water use; surface water resources; groundwater resources; water management;

\section{INTRODUCTION}

The territory of Mongolia is divided into three drainage basins, namely, Arctic Ocean, Pacific Ocean and Endorheic basin that provide water resources the year round. The $10.56 \mathrm{~km}^{3}$ of $609.5 \mathrm{~km}^{3}$ water resources on the Mongolian territory are usable resources. Water availability from groundwater and surface water resources are similar, but the renewal rates are totally different [1]. Mongolia ranks at the $102^{\text {nd }}$ place from among other countries in terms of total water resources [2] and at the $45^{\text {th }}$ in terms of freshwater resources per capita [3]. Mongolia also ranks at the $55^{\text {th }}$ place among other countries implicating high risk in terms of overall water risk, including water stress, water depletion, seasonal variability, no sanitation and no or unimproved drinking water [4].

*corresponding author: ayur@must.edu.mn

https://orcid.org/0000-0002-3815-1782

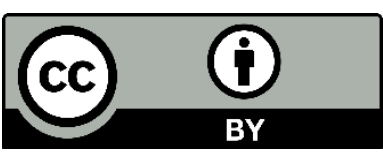

The Author(s). 2021 Open access This article is distributed under the terms of the Creative Commons Attribution 4.0 International License (https://creativecommons.org/licenses/by/4.0/), which permits unrestricted use, distribution, and reproduction in any medium, provided you give appropriate credit to the original author(s) and the source, provide a link to the Creative Commons license, and indicate if changes were made. 
At the national level, most of the aimags are at an extremely high risk of drinking water shortage (Figure 1) and at a high risk of water scarcity (Figure 2). In the South Gobi region, lack of proven groundwater resources, and lack of data on water extraction and consumption makes it difficult to accurately identify related risks. Mongolian water accounting is consolidated with the government administrative body in charge of nature and environmental matters. As of 2016, Mongolian water use amounted to 494 million $\mathrm{m}^{3} /$ year [5], and 570 million $\mathrm{m}^{3} /$ year in 2018 [6], which is an indication of drastic increase in water usage. Mongolia uses less than $1 \%$ of its total water resources, including $0.01 \%$ of surface water and up to $4 \%$ of groundwater. These figures are becoming bigger rapidly in the Central and the South Gobi regions [9].

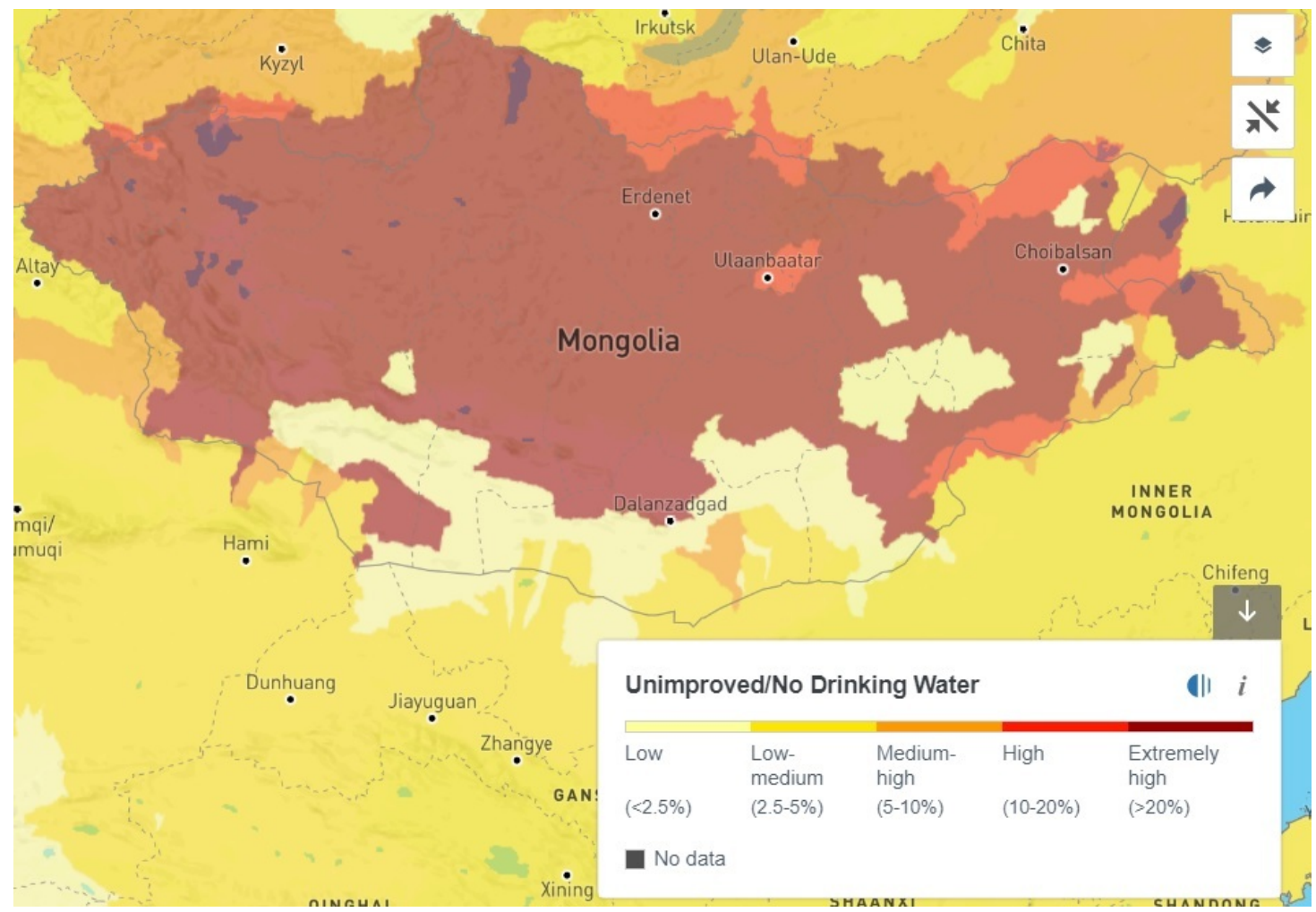

Figure 1. Percentage of people living without safe drinking water or no drinking water facility [4] 


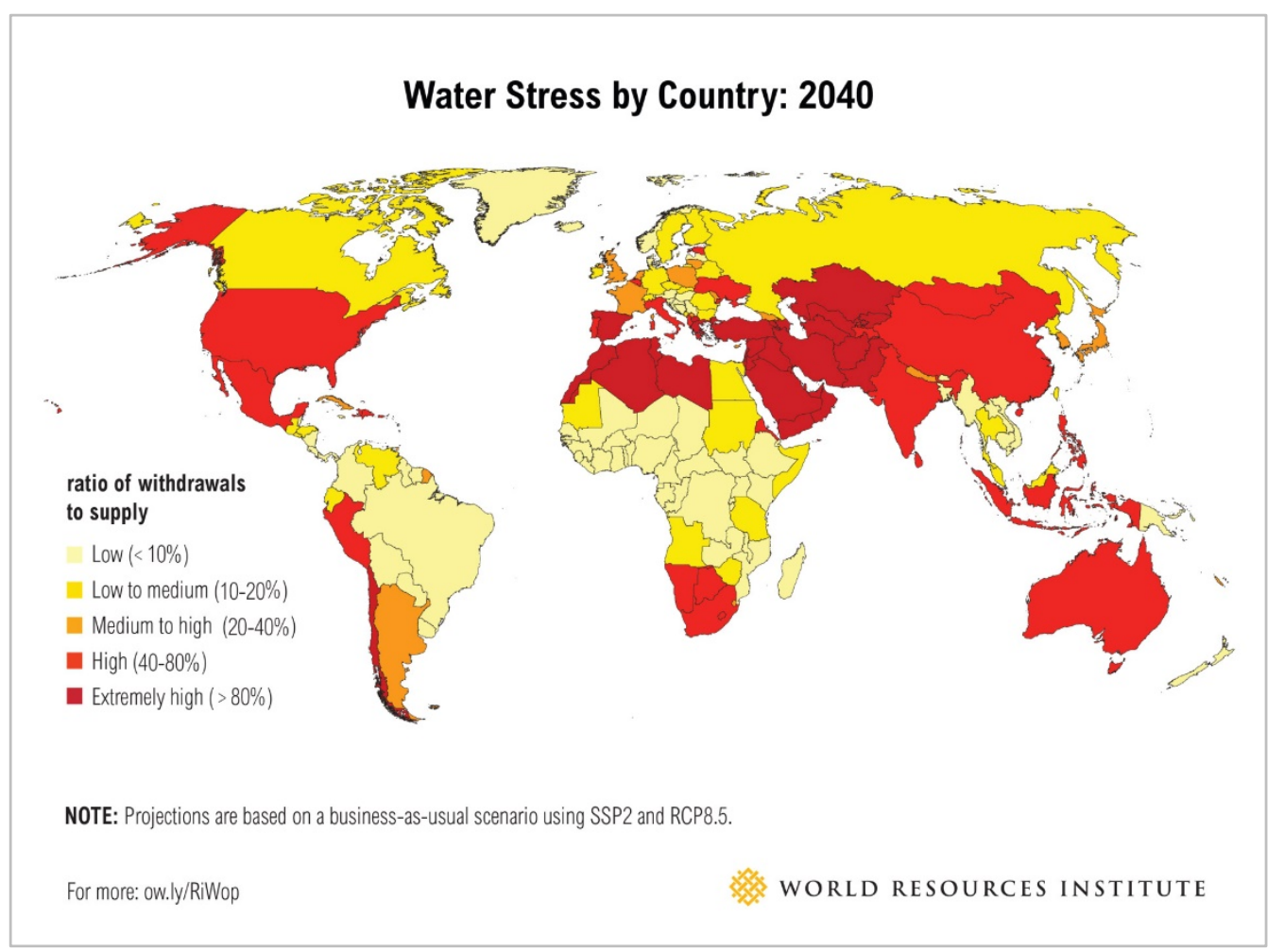

Figure 2. Water stress by 2040: Ratio of withdrawals to supply of water resources [7]

Especially in the last two decades, mining has been developing rapidly in the South Gobi region (Umnugovi, Dundgovi, and Dornogovi), which has been contributing to overall economic and social developments. The rapid growth in the mining industry in the region is backed by the existing groundwater resources and the country is planning to use groundwater resources in future accordingly. However, many studies have been warning that the limited groundwater resources in the South Gobi region may not be able to meet the growing demands in the future. These studies are often based on high, medium, and low water demand in comparison to available water withdrawals. For example, a World Bankinitiated assessment of groundwater resources in the South Gobi region, carried out in 2010, estimated that water shortages would occur in the region from 2023 and consumption would exceed the abstraction rate [8]. According to the study, water use in the South Gobi region will reach 371 million $\mathrm{m}^{3} /$ year by 2030 . Another study conducted by the international consulting firm McKinsey in 2014 stated that the South Gobi groundwater resources will become insufficient by 2020 due to high demand of mining industries. Their research projected the water demand of 197 million $\mathrm{m}^{3} /$ year by 2030 . Those predicted water demands are slightly overestimated compared to experiences of the past years, but all the same, they serve as an important background for further research. The 2030 Water Resource Group (WRG) projected low, medium and high water demands by 2030 [9] and 2040 [20] in the South Gobi region in 2014, thereafter focusing prioritization on reducing water use. According to the $2030 \mathrm{WRG}$, water shortages are expected in the South Gobi region from 2030 from medium to high demand [9]. The 2030 WRG updated their previous study on water demand and supply gap focusing mainly on Umnugobi aimag, the Centre of large mining operations in the South Gobi region and has extended the period until 2050 reflecting the long-term development policy "Vision 2050" [21]. 

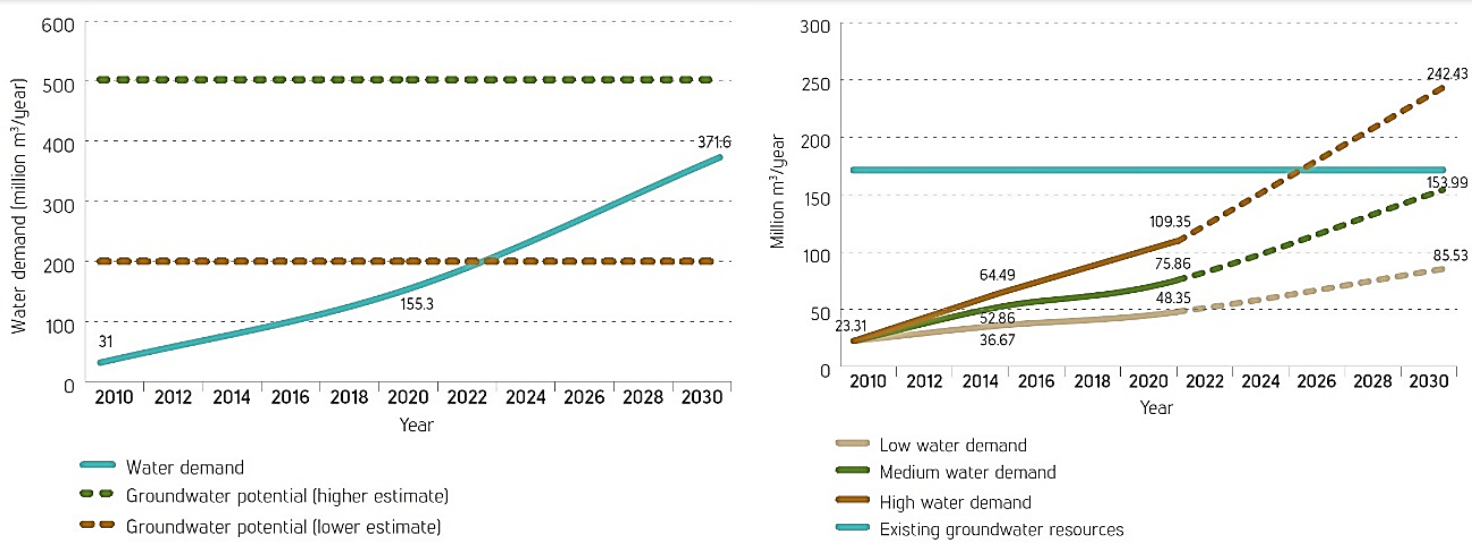

Figure 3. Water demand and available groundwater withdrawal: First figure after Tuinhof \& Buyankhishig (2010) and the second figure after the 2030 WRG (2014) [9]

The latest water demand projections for the South Gobi region were carried out to develop an integrated water resources management plan for the three main Gobi basins. Summing up the demands in the three Gobi aimags, it has been estimated that water demand will reach 140 million $\mathrm{m}^{3} /$ year by 2030 and water scarcity could happen in some of the soums - rural districts in the South Gobi region [10] [11] [12].

In this study, we attempted to fill in the gaps left by previous studies regarding the impact of climate change, and conducted a detailed evaluation of water resources, studied the water resources and demand projections of

\section{MATERIALS AND METHODS}

\section{Water system dynamics model for the South Gobi region of Mongolia}

A system dynamics model could be applied to all types of complex systems like water system and in the studies into linear and nonlinear relationships between the component or variables, which are the tasks of the system approach [13]. The water system dynamic model developed in this study is a combination of stakeholders that causally interact and impact with each other in a quantitative and qualitative way, depending on the legal regulation enacted.

There are many experiences in which system dynamics models have been used to implement system-wide analysis, such as implementing integrated water resource management plans, defining water demands and abstractions, optimizing new services, and optimizing institutional structures [14]. the South Gobi region namely Umnugovi, Dornogovi and Dundgovi aimags until 2050, using system dynamics modeling approach. Developed system dynamic modeling for the water system is a suitable tool for researching and decision making process and is able to be updated including direct and indirect effects in the framework of the water system which contains the water users, different types of stakeholders and government agencies. Previous studies on water demand projection solely relied on the trends of historical water use and did not study the interrelationship between the stakeholders in the water system $[8-12,20,21]$.

There is no industry that does not use water. Proper allocation and management of water resources is an important part of regional development, especially in areas with limited water resources. The nexus between water user and supplier is regulated by the government to secure the demand by the safe withdrawal, which requires a suitable decision support tool in better organizational structure. In this respect, system dynamic approach is a promising tool to understand and evaluate water management activities both in the research and decision making processes.

A model involving all water stakeholders in the South Gobi region has been developed within the Vensim system dynamics modeling environment, as shown in Figure 4. The purpose of the model is to assess whether the South Gobi region will be able to meet its water resources and growing demands by 2050, and 
to evaluate all factors that may affect water use, such as economic development, population growth, migration, and livestock productivity with focus on grazing capacity and climate change outlooks. The model is designed to provide forecasts of dependent variables for water use based on 2015-2019 baseline data for water use, population and the results of relevant international research on climate change projections. Depending on the concept as well as the size of the model and the level of complexity, the model is structured into four closely interconnected modules. The modules are:

- Module 1: Water resource balance in the South Gobi region,

- Module 2: Projections for mining water demand in the South Gobi region,

- Module 3: Projections for agricultural water demand in the South Gobi region, and,

- Module 4: Projections for industrial and drinking water demands in the South Gobi region.

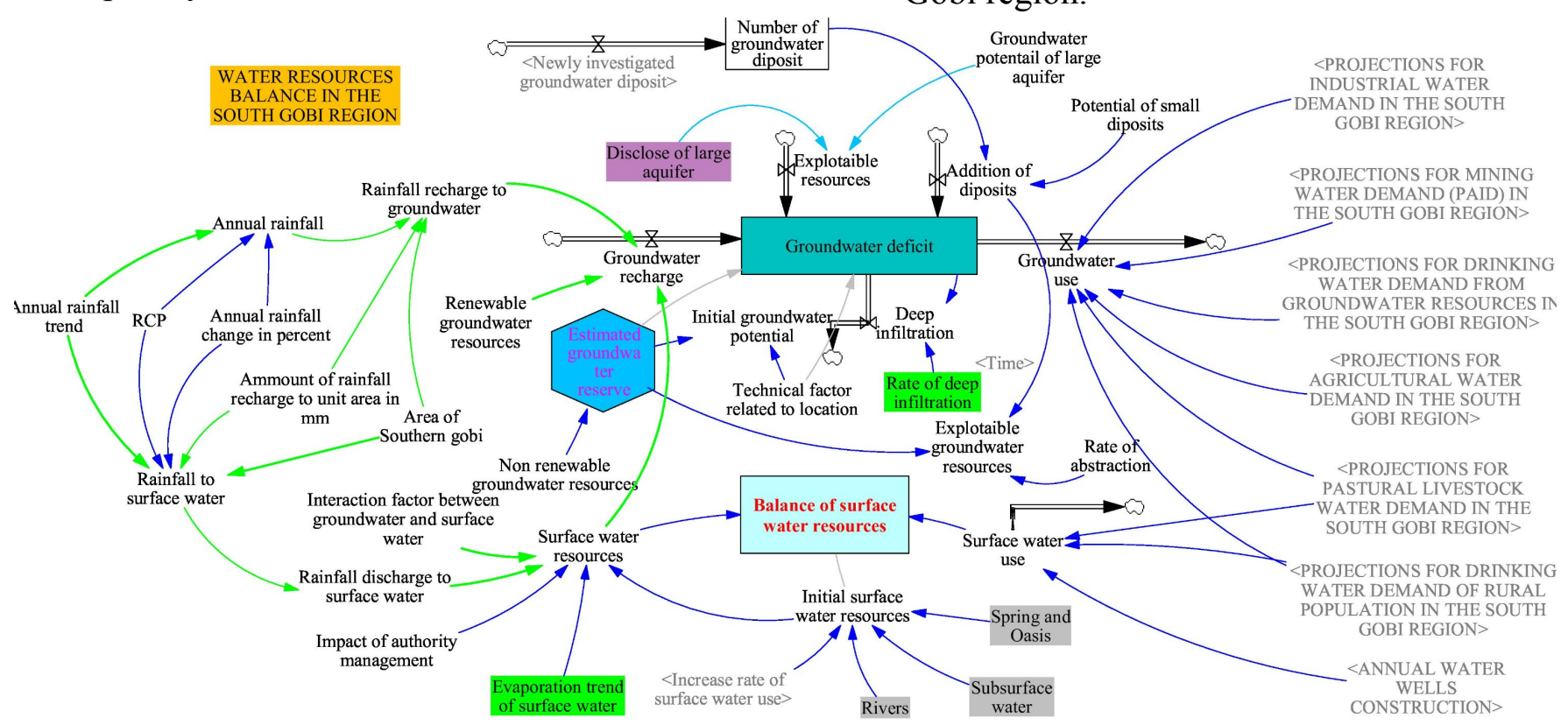

Figure 4. A system dynamics model for the South Gobi region water balance

In this model, water resources are considered as surface and groundwater resources and their users respectively. There are water users, such as pastoral livestock and population in the countryside that use water from both the resources. The model assumes that up to 40 per cent of pastoral livestock and up to 60 per cent of rural population would be supplied by groundwater to reduce the water stress by 2050. Most of the researches conducted have considered the availability of surface water resources in the South Gobi region as zero and is excluded from analysis. However, in reality, natural water springs, oasis, shallow ground wells and lakes in the South Gobi region provide water to wild life, pastoral livestock and rural human population. Thus, the model is the first to estimate surface water availability and the demand projections that could be managed by surface water resources with better management.
The current system dynamics model is markedly distinct from the previous studies $[5,8-12,20,21]$ on the projection of water demand in terms of the concept that is statistical based on the historical data for water demand and other interconnected casual factors from stakeholders. The model computes water demands only in one scenario, which assumes sustainable development keeping current achievement of development rate as 'business as usual' and computes water resources in three scenarios taking into account global warming factors and proven trends [19]. The scenarios are the current rate of climate change prescribing 'business as usual', RCP2.6 for keeping climate change at lower rate and RCP6 for bad scenario as climate crises.

As one of the final dependent variables in the model, ground water deficit is computed as follow: 


$$
Y_{g}=\int_{t_{0}}^{t}\left(X_{1}+X_{2}+\cdots+X_{n}\right) d s+Y_{t}
$$

where $Y_{g}$ is the time function of groundwater deficit, $X_{i, i}=(1, n)$ is the time functions of water input and output, which are renewal of precipitation, groundwater recharge, water withdrawal and water resources added by groundwater development, $Y_{t}$ is the proven available groundwater resources at the baseline year in the South Gobi region, $t_{0}$ is the baseline year when the computation starts and $t$ is the end year of the computation.

Another final dependent variable is the surface water balance, $Y_{s}$, depending on the amount of precipitation and water consumption in a given year:

$$
Y_{s}=X_{1}+Y_{t}
$$

where $X_{1}$ is the total available surface water resource in the South Gobi region and $Y_{t}$ is the renewal water resources by precipitation.

The model has a total of 4 modules, as listed above, integrating 6 differential equations, as two of them given in Eq.(1) and

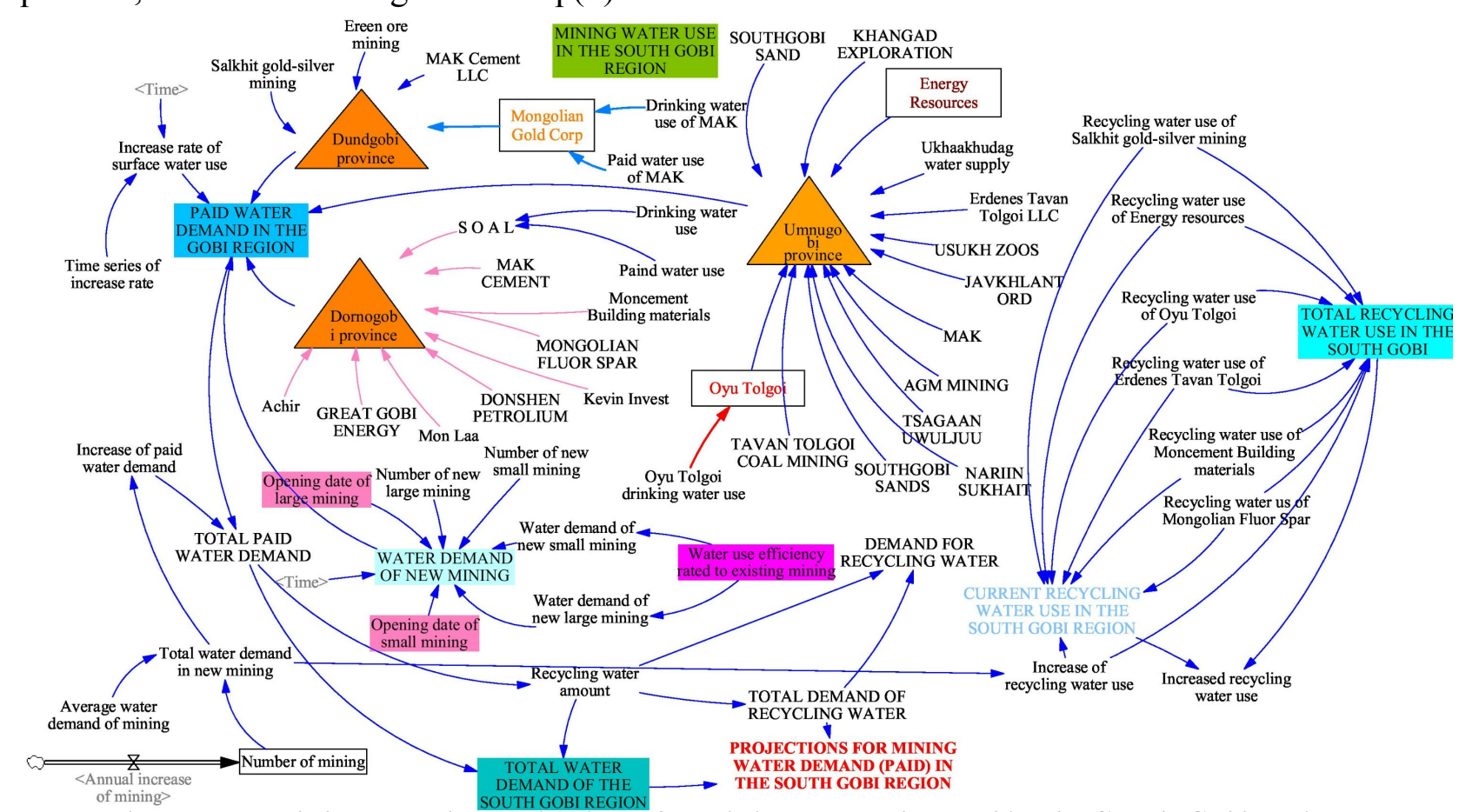

Figure 5. Module example: Projections for mining water demand in the South Gobi region

Mine water demand is the sum of the amount of paid water consumed and the amount of water reused, which depends on the efficiency of mineral production and the
Eq.(2) and 50 probabilities and statistical equations with more than 100 variables and parameters incorporated. The modules in the models are briefly described in the following sections.

\section{Modules in the model}

The largest water user in the South Gobi region is the mining sector. In this paper, the module computing water demand of mining industry has been selected as a demonstration example of other modules. Projections for the mining water demand module computes the water demand projections for mining in the region based on historical water use data and mining production data of each operating mine in the region and also computes the future demands of existing and future mining projected by statistical models, which takes into account mining licenses issued ${ }^{1}$. Mining water demand is classified into paid and reused or recycled water, as shown in Figure 5, and the paid water demand is the amount of water to be extracted from natural water resources.

\footnotetext{
${ }^{1}$ Data available at https://www.eic.mn/mining/
} 
while existing mining are modeled in an explicit manner, where each mine is visible. In the model, large scale strategic mining is modeled with a manual input. Following reasons justify the manual input:

- The start-up of a large-scale mine is highly dependent on political decisions and investment, and is unlikely to take place without political support.

- In case of establishment, the water consumption of large-scale mines will be higher than small- to medium-scale mines and will have significant impact on the system dynamics and water resource balance. Those impacts need to be embedded into the model and carefully investigated.

Due to the fact that the number of annual exploration licenses and the historical data from which mining licenses have been issued are uneven, the model applies probabilistic approach to compute annual increase in smalland medium-sized mines. The model applies functions to calculate the amount of water demand for some existing and new mines to operate at full capacity until their decommissions within 2050. Other impacts of the mining industry, such as population and social services growth, are linked to the other modules, which calculate the water demands for corresponding dependent variables. In such a way, the modules in the dynamic model of the water stakeholders are interconnected, and changes in the quantity of one dependent variable affects another.

The system dynamic model for water demands has been developed in an attempt to fully reflect such water stakeholders and their participation in the economy, and the impact on water resources. For example, in the module that computes water demands for pastoral livestock and agriculture, the number of livestock depends on the grazing capacity of pastures, irrigated area, and population growth in the South Gobi region, while agriculture depends on water availability and vegetable demands in the region.

\section{Historical data for the model}

Mining water use, industrial and social service water use and urban water use data are taken from the Annual report of MNET [6] [16] and data which is not public were collected upon request from MNET with third-party restriction. In addition, some data on mining water consumption were collected from the dataset of Voluntary Code of Practice and other sources [10-12] and annual reports of water users [17]. Water demand of livestock, rural population and agricultural area were calculated according to the norms of unit production, approved by the Order A/301 of the Minister of Environment, Green Development and Tourism, dated July 30, 2015. Water consumption of those stakeholders are merely measured and recorded [18]. More detailed description about data used for this study can be found in [22].

Precipitation and evaporation forecasts are derived from historical data using a nonlinear forecasting method. Climate change scenarios RCP2.6 (minimizing climate change by declining $\mathrm{CO}_{2}$ by 2020 and going to zero by $2100)$ and RCP6 $\left(\mathrm{CO}_{2}\right.$ emissions peak around 2080 , then decline) were used to estimate the impact of climate change on the surface and groundwater resources of the South Gobi region. The model directly adapts the results of the Global Climate model [19].

\section{Validation of the water system dynamics model}

The validation of the model and its outputs are important. It is certain that the results of the water system dynamics model depend entirely on the quality and timing of the historical data. Data series used is a relatively short period of time and is obviously not effective for exact projection. In this study, the outputs of the model are validated by using two different and unrelated calculations. For example, mining water demand projections are calculated by:

- using non-linear incremental regression equation produced from the water use data between 2015 and 2019, and,

- using the water amount used for unit production from 2015 to 2019 and production forecasts to project the future water demand.

The results obtained by these methods were close to the historical data of 2015 to 2019 , which show that the model could provide reliable outputs for future water demand 
projection. For instance, the model shows that the mining industry had used 241 million $\mathrm{m}^{3} /$ year $(239.56)^{2}$ in 2019 , from which paid water was 38.59 million $\mathrm{m}^{3} /$ year (28.97), while reused water was 203.1 million $\mathrm{m}^{3} /$ year
(209.34) in 2019. The validation results for the mining water consumption for using natural water extracted are shown in Figure 6.

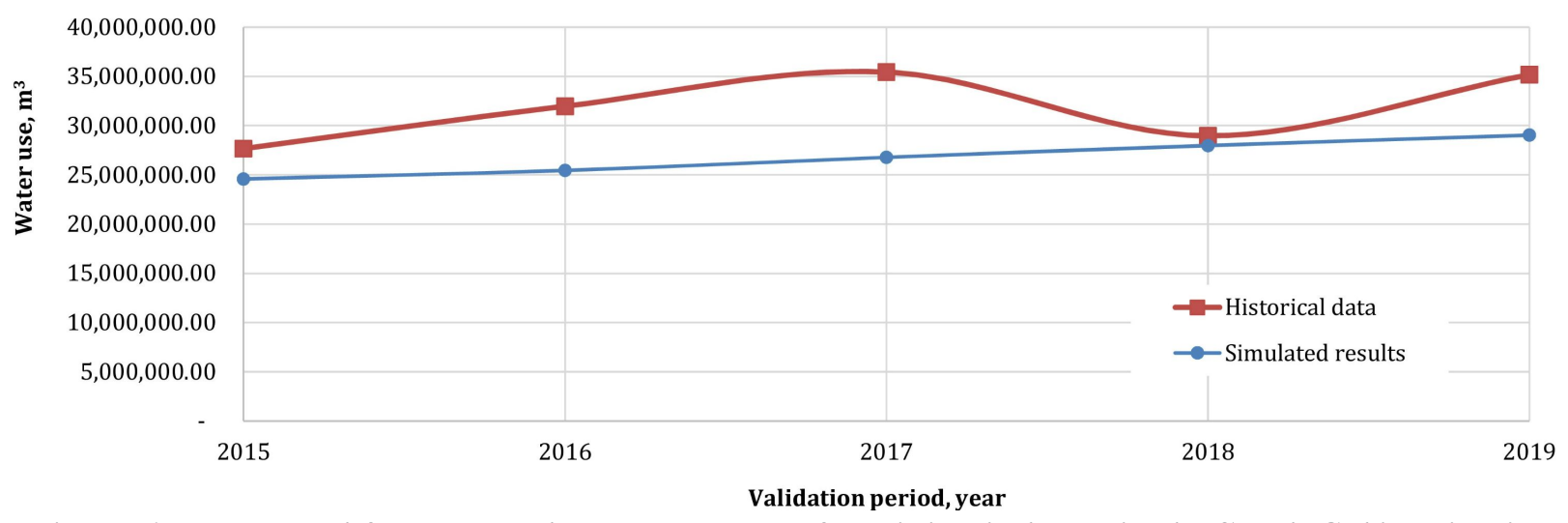

Figure 6. Water used from natural water resources for mining industry in the South Gobi region in m $^{3}$

When the other results from the model were compared with historical data, the confidence range of the model results was about
70 to 90 per cent. This suggests that the model is sufficient for decision making, planning and research.

\section{RESULTS AND DISCUSSION}

This section provides detailed discussions of the output of the model. According to the water system dynamics model involving all stakeholder in water sector, groundwater withdrawal in the Gobi region is expected to increase from 67 million $\mathrm{m}^{3} /$ year in 2015 to 258 million $\mathrm{m}^{3} /$ year by 2050 . Large water users, the mining industry, will use 913 million $\mathrm{m}^{3}$ water per year by 2050 , of which 145.8 million $\mathrm{m}^{3} /$ year is paid water and 767.2 million $\mathrm{m}^{3} /$ year is reused water. This shows that water demand is increasing due to the rapid development of the mining industry, resulting also in population and services growth. Figure 7 shows the water demand projections for the South Gobi region for each water use sector.

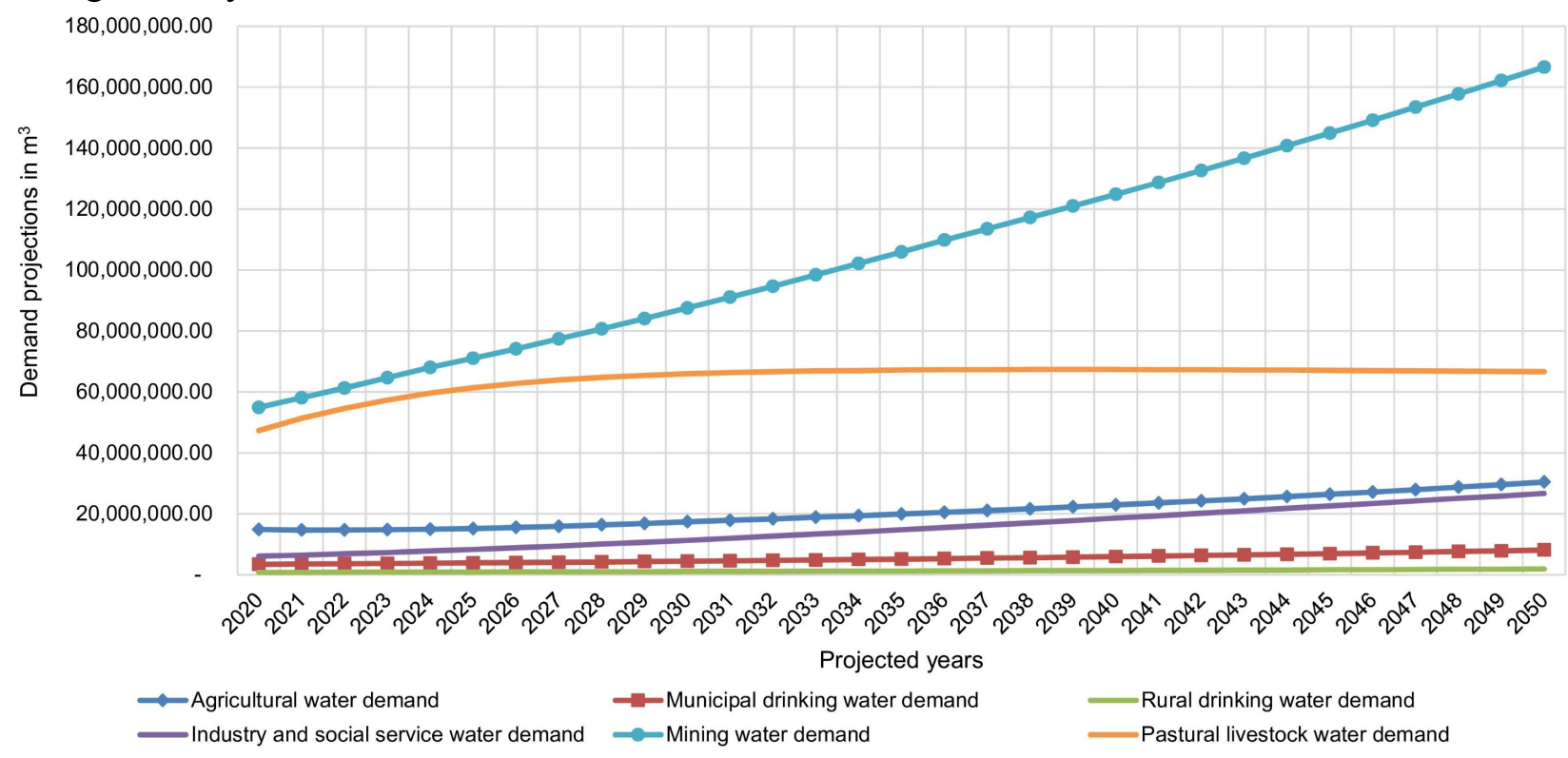

Figure 7. Water demand projections by each water use sector for the South Gobi region by 2050

\footnotetext{
${ }^{2}$ The historical data is given in parentheses
} 
The next two largest sectors of water users are pastoral livestock and agricultural sectors. Optimistically, assuming that the number of livestock lost in $d z u d$ or severe winter is likely to be small, the number of livestock will reach grazing capacity of the pasture area in 2035, and the growth will gradually either decline or stabilize. This figure is expected to remain unchanged in terms of water resources and water demand by pastoral livestock, which is expected to be about 66 million $\mathrm{m}^{3} /$ year by 2050 . Drinking water for the municipal population of the South Gobi region will be supplied by groundwater and the total demand will reach about 7.7 million $\mathrm{m}^{3} /$ year by 2050. While the industrial and social services water demand, which is largely dependent on the population and mining operations, will reach 36.25 million $\mathrm{m}^{3} /$ year by 2050 .

Total water demand projections to be supplied by water resources are plotted in Figure 8.

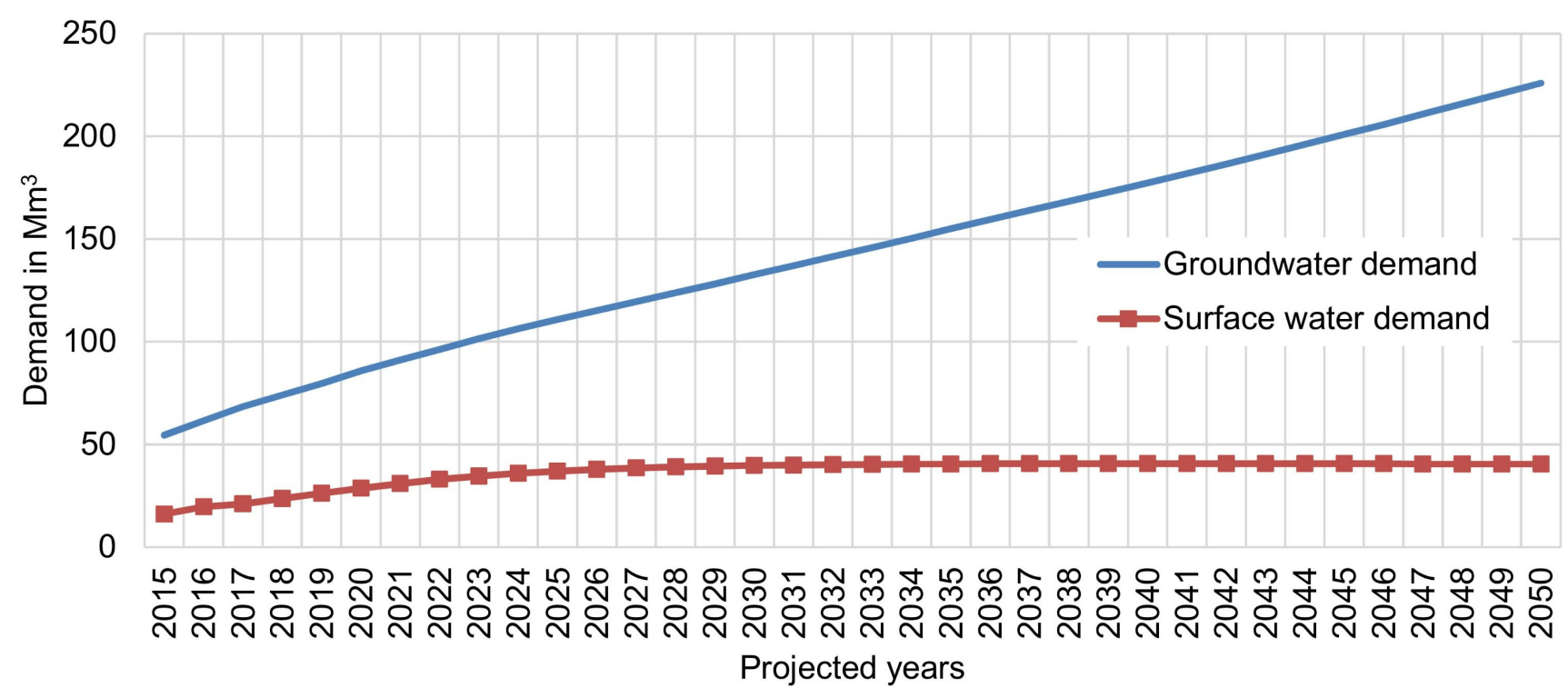

Figure 8. Projections for groundwater and surface water withdrawals by means of total water demands by 2050

In the South Gobi region, pasture irrigation is preferable with deep or shallow groundwater well, as surface water sources are either not guaranteed or evaporation losses are too high. Therefore, surface water withdrawal tends to decline in future. While increasing abstraction of groundwater indicates the need to properly allocate limited groundwater resources for all water stakeholders. Water demands of 149.6 million $\mathrm{m}^{3}$ year by 2030 , computed by the water system dynamics model, were nearly the same as the average scenario of World Bank projection (153.99 million $\mathrm{m}^{3} /$ year in [8]) and the projections (140 million $\mathrm{m}^{3} /$ year in [10], [11] and [12]) provided for in the integrated water management plans for Umnugovi, Dundgovi and Dornogovi aimags. And so, the total water demand projections by 2050 at 266.27 million $\mathrm{m} 3$ /year could be considered as a very plausible projection.
In the water system dynamics model, groundwater resources are mainly used for industrial, mining, municipal water supply and agriculture, and will also cover certain parts of rural and livestock water demand. As of 2020, total water consumption was solely supplied by groundwater resources. If this supply is expected to continue further, the deflection of groundwater resources shown in Figure 9, including the effect of climate change scenarios on the groundwater resource, could be experienced. Climate change directly impacts on the renewable groundwater resources and surface water resources in different time scales. The assumption is true that climate change has no impact on deep and non-renewable groundwater resources. Renewable groundwater resource will remain sustainable if the world can reduce $\mathrm{CO}_{2}$ emission working with RCP2.6 scenario. Under this scenario (projections with RCP2.6 in Figure 9) the 
available groundwater resources will not meet the demands of the South Gobi region by 2036 and water scarcity will occur after 2044.

The available groundwater resource will be sufficient until 2040 unless drastic measures are taken to maintain the current rate of economic growth and reduce greenhouse gas emissions in the scenario with current rate of climate change.

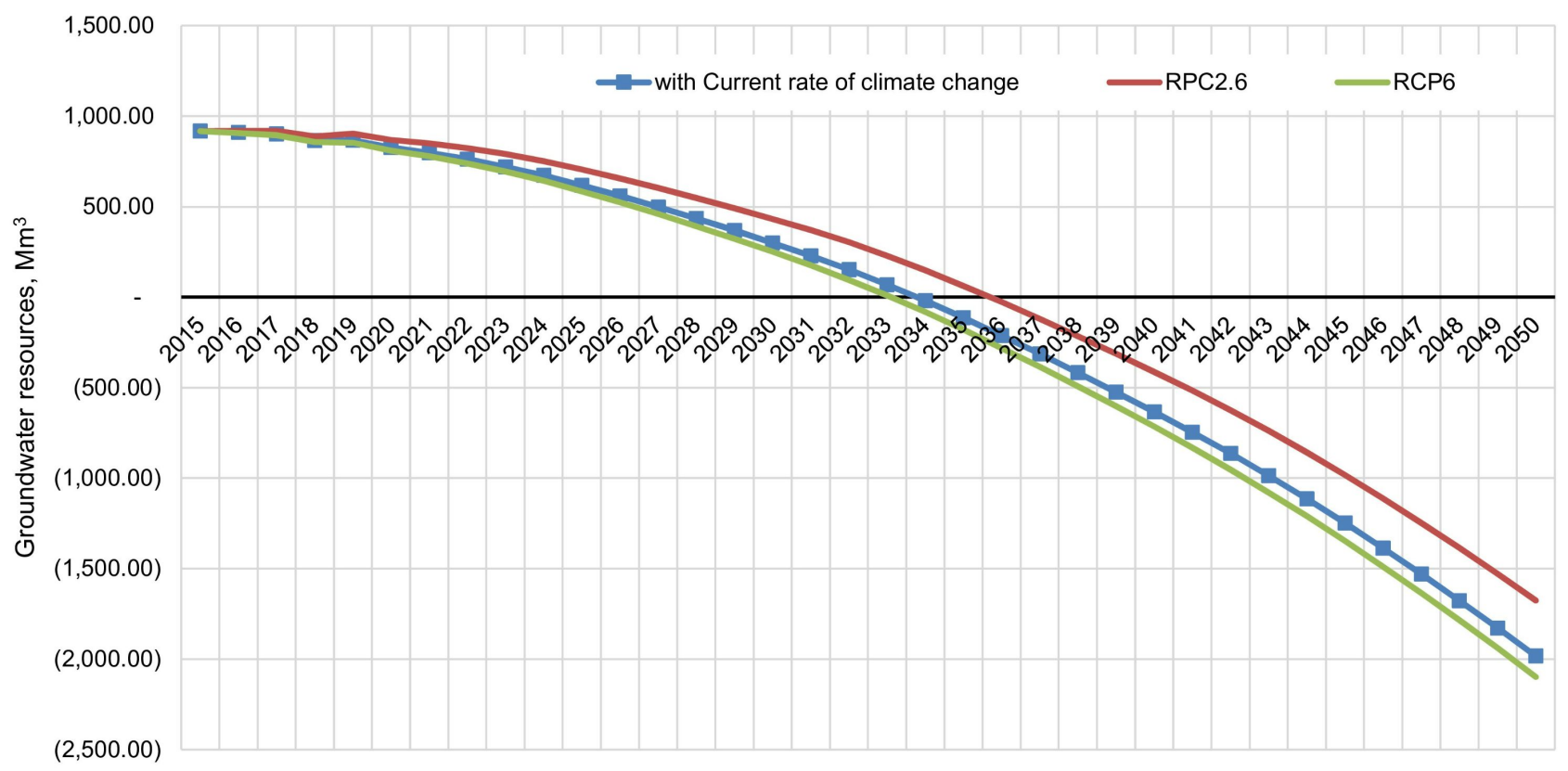

Figure 9. Depletion of groundwater resources in the South Gobi region affected by the selected climate change scenarios (million $\mathrm{m}^{3} /$ year)

With high economic growth and increased greenhouse gas emission (projections with the RCP6), the available groundwater resources in the South Gobi region are projected to be depleted by 2034 .
The changes in the surface water resources are higher than that of groundwater resources. The model predicts that the available surface water resources will be around 20-50 million $\mathrm{m}^{3} /$ year, which would be highly dependent on the annual precipitation.

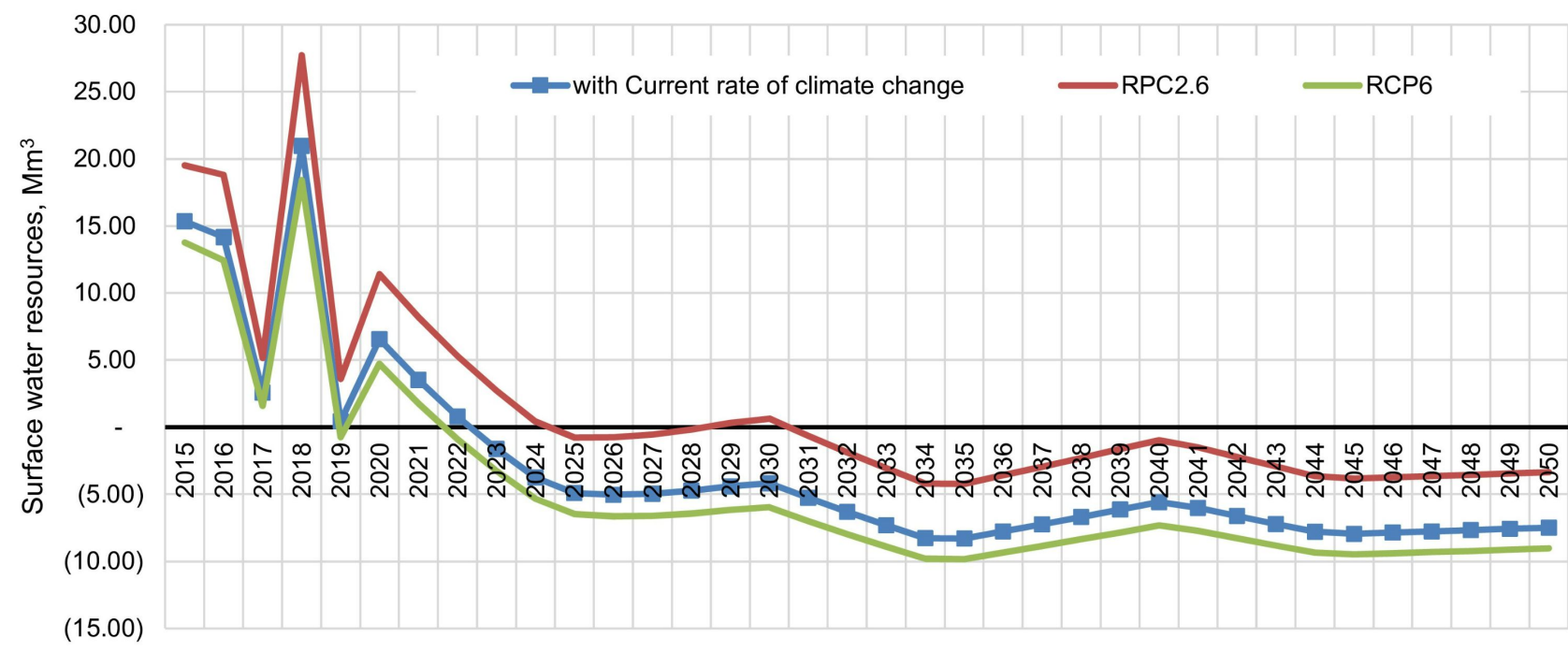

Figure 10. Difference between the annual available surface water resources and water abstraction from surface water resources (million $\mathrm{m}^{3} /$ year)

The increase in water demand, which is supposed to be met by surface water resources, is likely to exceed the available surface water resources from 2023 under all scenarios. 
In some year when rainfall is high, water resources can surpass the demand and those figures with usual projections and projections with RCP2.6 can be seen in Figure 10 around 2030 and 2040 respectively. However, in years with less rainfall, surface water user might fall at risk. The risk of surface water scarcity has also been observed in previous years as evidenced by the data reflecting drought, drying

\section{CONCLUSIONS}

The system dynamic model for water stakeholders to project water demands for the South Gobi region until 2050 has been developed, including all possible and available influencing factors. In this model, the available water resources and corresponding water demands are computed separately as ground and surface water respectively. The water demand in the South Gobi region is projected under the current rate of economic development, while groundwater and surface water resources are computed with three scenarios of climate change, reflecting global response to the impact which is the main contribution of this study. The available groundwater resources will not be available from 2036 and the available surface water resources, depending on annual precipitation, will not be available from 2023 for demand. Therefore, some measures that can be evaluated in the model can be promising in reducing potential risks, such as developing water use and water resources data base at certain time interval and making corresponding analysis, planning and implementing water resource

\section{REFERENCES}

1. Dolgorsuren.G, Gerelchuluun.J, Puntsagsuren.Ch, Baldandorj.Ts, Born. Ya and Linden.B, "Integrated water resources water management plan of Mongolia,” MNET, Ulaanbaatar, 2013.

2. CIA, "The World Factbook," Central Intelligence agency, 2015.

3. FAO, "Renewable internal freshwater resources per capita (cubic meters) Country Ranking,” AQUASTAT, 2014. rivers, lakes and ponds. Therefore, it is necessary to keep the water consumption sourcing from the surface water resources at certain level to reduce water risk for the users. In other words, there is a need either to improve pasture irrigation and rural drinking water sources, or to increase surface water resources with low losses.

development projects to increase local water resources, adapting water efficient technologies for large water users, implementing feasible long-distance water transmission projects, and improving water resource allocation and water governance, and implementing research-based public policy or political decision. Future outlook will be focused on the effectiveness of the above measures in water management by means of water system dynamics modelling. As limitation of the current model, regional and local uncertain event in the society that could bring unexpected changes in the water use like COVID-19 pandemic should be considered with relevance. It should be noted that existing data base for the water demand study is not sufficient to reveal the current status of the water security in the region and it should be improved in terms of usefulness and openness of such data for further research and better decision-making process.

Acknowledgement: This research was a part of the feasibility study for the establishment of a water research center funded by the Umnugovi aimag Governor's Office.
4. WRI (World Resources institute), "National and sub-national water risks atlas," World Resources Institute, Aqueduct, 2019.

5. Ganzorig.Sh, Onon.O, Bayarjavkhlan.M and Saranmandal.D, "Assessement of water use in Mongolia," Problems in hydraulic engineering, Ulaanbaatar, 2018.

6. MNET, "Reports on the states of the environment of Mongolian," Ulaanbaatar, 2018. 
7. WRI (World Resources institute), "Aqueduct projected water stress country rankings," World Resources Institute, Washington, 2015.

8. A. Tuinhof and N. Buyankhishig, "Groundwater Assessment of the South Gobi Region, Mongolia Discussion Papers, East Asia and Pacific Sustainable Development Department.," Mongolia Discussion, Washington, D.C.: World Bank., 2010.

9. WRG (2030 Water Resources Group), "Mongolia: Targeted analysis of water resources management issues," 2030 Water resources group, Ulaanbaatar, 2014.

10. Dunar-Od LLC, "Base study report for integrated water resources management plan for the Galba-Uush Doloodiin Gobi water authority," MINIS, Ulaanbaatar, 2018.

11. Mongolian Association of Hydrogeologists, "Base study report for ntegrated water resources management plan for the Trans-Altai Gobi water authority,” MINIS, Ulaanbaatar, 2018.

12. 'Us hugjliin tulhuur' NGO and 'Unu munkhiin Undarga' NGO, "Base study report for integrated water resources management plan for the Umard Gobiin guveet-khalkhiin dundad tal water authority,” MINIS, Ulaanbaatar, 2018.

13. J. Forrester, Principles of System, Massachusetts: Productivity press, MA, Cambridge, 1968.

14. C. Qi and N.B. Chang, "System dynamics modeling for municipal water demand estimation in an urban region under uncertain economic impacts," Journal of environmental management, pp. 1628-1641, 2011.

15. MNET (Ministry of Nature, Environment and Tourism), "Report on water use assessment for large water users," Ulaanbaatar, 2017.

16. MNET (Ministry of Nature, Environment and Tourism), "Spent reports on water fee," Ulaanbaatar, 2014-2019.

17. ICMM and IFC, "Shared Water, Shared Responsibility, Shared Approach: Water in the Mining Sector," ICMM; IFC, Washington, 2017.

18. MNET (Ministry of Nature, Environment and Tourism), "Compilation of water related legal acts,” Ulaanbaatar, Mongolia, 2020.

19. JMOE, "Climate Change in Mongolia: Outputs from GCM," Ministry of Environment, Japan, Tokyo, 2014.

20. WRG (2030 Water Resources Group), "Prioritized solutions to close the water gap: Hydro-economic analysis on the coal mining regions in Mongolia's Gobi Desert," World Bank Group, 2016.

21. WRG (2030 Water Resources Group), "Hydro-economic analysis: Prioritized solutions for demand reduction and supply augmentation in the mining and heavy industry region in South Gobi," World Bank Group, 2021

22. HDI (Hydrodesign Innovation LLC), "Feasibility study for water research management center in the Southern Gobi of Mongolia,” Ulaanbaatar, Mongolia, 2019. 